annually. This is about 35 US cents (23 pence) per capita and is considerably less than the 18 US dollars per capita spent in the United States. ${ }^{8}$ An analyst of the tobacco industry suggests that British-American Tobacco considers the market in Mauritius saturated, with little potential for increases in volume, and with no new market segments to be opened up there is limited scope for product differentiation. Limited opportunity to break the strong cultural resistance to women smoking is seen. This suggests that Mauritius has avoided massive promotional activity by tobacco companies compared with other developing nations. In the absence of this, any health promotion and legislative efforts, including tax increases, seem to have been more effective and sustained than elsewhere. ${ }^{14}$

Mauritius is a rapidly developing country that has made great gains in tobacco control in the absence of the expensive antismoking campaigns seen in developed countries. It seems that a lack of excessive promotional activity by tobacco companies has led to more effective legislative and health promotion efforts. Increased taxes in conjunction with slower economic growth may have played a major part in reducing smoking behaviour. Reductions in smoking prevalence across income categories support this supposition. These observations support the premise that curbing the efforts of tobacco companies in low and middle income countries is central to initiatives for tobacco control.

We thank the people of Mauritius, Australia, and Finland who have been involved in the planning and conduct of noncommunicable disease research activities in Mauritius since 1987.
Contributors: HSC conceived the rationale for this paper, analysed the data, and wrote the paper. JWW assisted in data analysis and in critical review of the manuscript. MPdeC planned and coordinated the 1998 survey and helped with the analysis and review of the manuscript. PC was involved in the design of the surveys and in initiating tobacco control initiatives in Mauritius. JT designed the survey instrument and reviewed the paper. PZZ, as head of the research group, planned and monitored the conduct of all three surveys and is the guarantor for the paper

Funding: The surveys were supported by a grant from the US National Institutes of Health (No DK-25446) and the Government of Mauritius.

Competing interests: None declared.

1 Hill DJ, White VM, Scollo MM. Smoking behaviours of Australian adults in 1995: trends and concerns. Med J Aust 1998;168:209-13.

2 Garfinkel L. Trends in cigarette smoking in the United States. Prev Med 1997;26:447-50.

3 World Bank. Curbing the epidemic. Governments and the economics of tobacco control. Washington, DC: World Bank, 1999. www.globalink.org/tobacco/ $\mathrm{wb} /$ (accessed 2 Feb 2000)

4 Dobson AJ, Kuulasmaa K, Moltchanov V, Evans A, Fortmann SP, Jamrozik K, et al. Changes in cigarette smoking among adults in 35 populations in the mid-1980s. Tobacco Control 1998;7:14-21.

5 World Bank. Africa region live database. www.worldbank.org/data/ databytopic/ (accessed $23 \mathrm{Feb} 2000$ )

6 Dowse GK, Gareeboo H, Zimmet PZ, Alberti KGMM, Tuomilehto J, Fareed D, et al. High prevalence of NIDDM and impaired glucose tolerance in Indian, Creole and Chinese Mauritians. Diabetes 1990;39:390-6.

7 Centers for Disease Control and Prevention, Office on Smoking and Health. Smoking prevalence among US adults. Tobacco information and prevention source. www.cdc.gov/tobacco/prevali.htm (accessed $11 \mathrm{Feb}$ 2000)

8 Centers for Disease Control and Prevention, Office on Smoking and Health. Domestic cigarette advertising and promotional expendituresUnited States, 1963-1994. Tobacco information and prevention source. www.cdc.gov/tobacco/adv-pro.htm (accessed 2 Feb 2000).

(Accepted 27 June 2000)

\title{
Increased mortality among Danish women: population based register study
}

Knud Juel

Even at the beginning of the $1950 \mathrm{~s}$, the prevalence of smoking among Danish women was as high as $40 \% .{ }^{1}$ In the 1980s the proportion of men and women who smoked cigarettes in Denmark was almost the same, which is unusual. Data from interviews and questionnaires showed that the proportion of heavy smokers had increased steadily among women over a long period: $1 \%$ (1953), 7\% (1970), 12\% (1980), 15\% (1987), and 18\% (1994). At the beginning of the 1990s, Danish women had the highest prevalence of smoking in the 87 countries in which smoking among women was recorded. ${ }^{2}$ The life expectancy of Danish women is shorter than that of women in other western European countries. ${ }^{3}$ Mortality from lung cancer and chronic obstructive pulmonary diseases among Danish women has increased greatly from the 1960s and is now by far the highest in Europe. ${ }^{3}$ To assess the impact of smoking on mortality among Danish women, we performed a register based study for the period 1951-95.

\section{Methods and results}

We calculated mortality attributable to tobacco use by Peto et al's method. ${ }^{4}$ They compared the death rates from lung cancer in a study population with those of a US group to derive an estimate of smoking rates in the study population (more lung cancer meant more smoking). They assumed that certain relative risks for smoking and important diseases related to smoking applied to all populations. These two sets of assumed statistics were then used to calculate population attributable risks for each of the major causes of death in each population.

Data on deaths and causes of death in Denmark are available in the Cause of Death Register of the National Institute of Public Health, which covers all deaths in Denmark since 1943. The data on deaths in other countries of Europe were derived from the World Health Organization's database.

The figure shows the risk of death among Danish women aged 55-84 since the beginning of the 1950s. The risk of mortality from any cause declined until the start of the 1970s and then increased slightly. In the absence of deaths attributed to smoking, the decline would have continued. The risk of dying of tobacco attributed causes increased steadily, from less than $1 \%$ of all deaths at the beginning of the 1950 s to about $25 \%$ of all deaths 40 years later.

\section{National Institute of Public Health, DK-2100, Copenhagen, Denmark \\ Knud Juel senior researcher kj@dike.dk}

BMJ 2000;321:349-50 


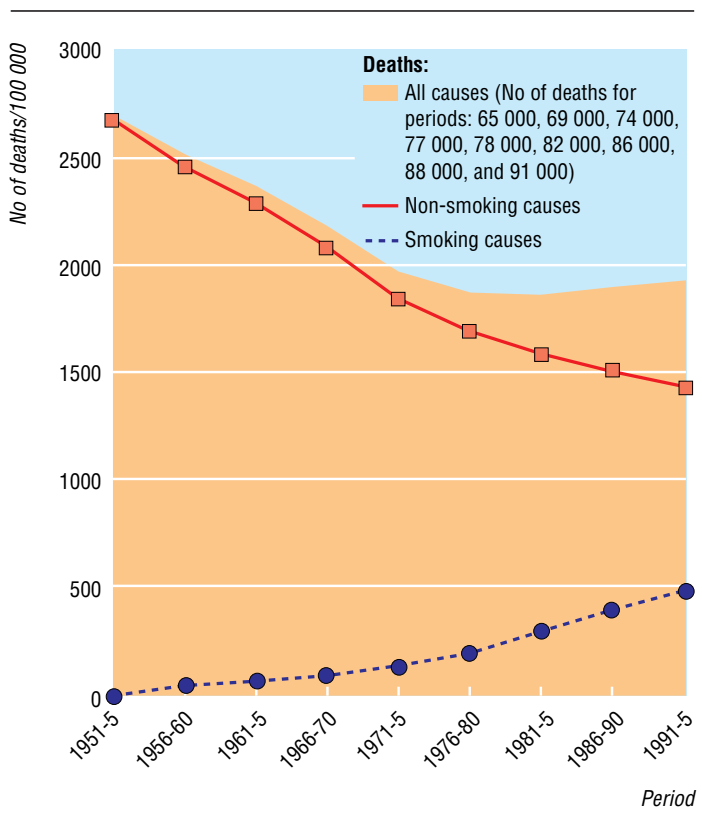

Trends in age standardised mortality (per 100 000, world standard) for deaths attributed to smoking and to causes other than smoking among women aged 55-84 in Denmark, 1951-95 women that is of most concern. Denmark is one of the few countries in which the estimated annual mortality from smoking is almost identical for men and women.

No country has yet experienced the full impact of smoking on women's health, ${ }^{5}$ but there is now strong evidence that when women have smoked cigarettes regularly for several decades the percentage of deaths attributable to tobacco approaches that of men. ${ }^{4}$ This situation has almost been reached in Denmark, and the trend may be a forerunner of a development that has begun or will begin in other European countries.

Danish life expectancy cannot be improved greatly without a substantial reduction in tobacco consumption. Furthermore, the present high proportion of smokers among adult Danes will continue to affect the mortality pattern far into this century. Clearly, if it were not for tobacco, Danish women would have experienced a considerable reduction in mortality.

Contributors: $\mathrm{KJ}$ is the sole author of this paper.

Funding: The study was supported by grants from the Danish Ministry of Health.

Competing interests: None declared.

1 Hamtoft H, Lindhardt M. Tobacco consumption in Denmark. Dan Med Bull 1955;2:213-20.

2 World Health Organization. Tobacco or health. A global status report. Geneva: World Health Organization, 1997.

\section{Comment}

Since the 1970s, Danish women in some age groups have experienced increasing numbers of deaths. This can be explained by the longstanding heavy use of tobacco.

The risk of dying of causes attributed to tobacco is still highest among men, but it is the trend among
3 Juel K, Bjerregaard P, Madsen M. Mortality and life expectancy in Denmark and in other European countries: what is happening to middle-aged Danes? Eur J Public Health 2000;10:93-100.

4 Peto R, Lopez AD, Boreham J, Thun M, Heath C. Mortality from tobacco in developed countries: indirect estimation from national vital statistics. Lancet 1992:339:1268-78.

5 Amos A. Women and smoking. Br Med Bull 1996;52:74-89.

(Accepted 26June 2000)

\section{A memorable patient \\ In favour of the weed}

In the summer of 1987 , before starting medical school, I worked in Bristol as a community service volunteer helping a young man with multiple sclerosis. His usual carer was away and I stepped in just in time to escort him on a trip to London that his old work friends had organised. Before his illness he had been a successful talent scout for a record company, and his old contacts had arranged a glitzy night out for him and his London friends, which included a limo, front seats at a Prince concert, and back stage passes.

The most disabling and distressing aspects of his condition were the spasms. The leg jerks threatened to launch him from his wheelchair, and he was unable to feed himself because of the frustrated efforts at finding his mouth. His speech was almost unintelligible and punctuated with startling bursts of volume. $\mathrm{He}$ required full nursing care, and his friends in London were keen to provide it for him during his trip. It was decided, however, that I should go so that I (as the Dr To Be) could be responsible for ensuring that he received the massive cocktail of antispasmodics that he had been prescribed to take at regular intervals.

Generously, he said that he would like me to participate in the big night out in its entirety.

I am ashamed to say that in my excitement I failed my only duty and forgot to pack any of his medications. As I was introduced to his friends, it soon became evident that, in his previous life, my charge had been an enthusiastic marijuana smoker. Everyone greeted him by presenting him with a celebratory joint and he was delighted. He was completely unperturbed that I had forgotten his antispasmodics, as he never felt them to be very beneficial. I did not voice my concerns at the amount of pot that he was happily smoking as I thought that I had no right, having forgotten all his medicines. I also hoped that any adverse effects of having suddenly stopped his medicines would be attributed to his own overindulgence.

It took over 48 hours before we could obtain a prescription to replace his antispasmodics, but by the time they arrived he was a changed man. Obviously delighted at being reunited with his friends and old vice, he had relaxed and his mood had improved, but also his spasms and rigidity had virtually disappeared. It was also possible to comprehend his speech (although the marijuana had not sharpened the quality). His friends, realising the cause of this, were quick to ensure that he was constantly in possession of a lit joint.

We had a wonderful night at the concert with the biggest thrill being how relatively well he was. This unscientific but dramatic display convinced me of the therapeutic potential that marijuana has for people with multiple sclerosis. This impression was strengthened by his quick return to his original condition when the cannabis supply diminished when he returned to Bristol and his limited funds.

Clare Tyler general practitioner, north Devon 